研究

\title{
Low Temperature Synthesis of Electrode Films from Silver- Palladium Alloy Powders for Multilayer Ceramic Devices
}

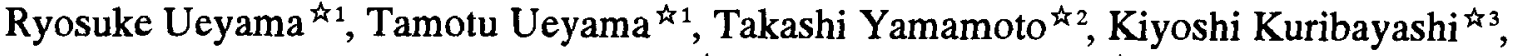 \\ Kunihito Koumoto ${ }^{\text {th }}$ and Tadashi Shiosaki ${ }^{\text {th } 5}$ \\ ${ }^{1}$ Daiken Chemical Industry Corporation Limited, 2-7-19 Hanaten-nishi, Jyoto-ku, Osaka 536-0011. \\ ${ }^{2}$ Department of Electrical Engineering, National Defense Academy, 1-10-20 Hasirimizu, Yokosuka 239-0811. \\ ${ }^{3}$ Department of Materials, Teikyo University of Science and Technology, 2525 Yatsuzawa, Uenohara-Machi, Yamanashi $409-0193$. \\ ${ }^{4}$ Dept.of Applied Chemistry, Graduate School of Engineering, Nagoya University, furou-cho Chikusa-ku, Nagoya 464-8603. \\ ${ }^{5}$ Graduate School of Materials Science, Nara Institute of Science and Technology, 8916-5 Takayama-Cho, Ikoma 630-0101.
}

Received January 17, 2000

\section{SYNOPSIS}

Physical and electrical properties of three types of Ag-Pd pastes, which consist of different metal fine powders, i.e., a coprecipitated powder, an agglomerated alloy powder made by heat treatment and a pulverized alloy powder produced by improved pulverization method, have been studied. The paste prepared from pulverized alloy powder showed a higher film packing density $\left(6.3 \mathrm{~g} / \mathrm{cm}^{3}\right)$ than those made of the other powders. The film consisting of pulverized alloy powder showed a lower expansion at around $500^{\circ} \mathrm{C}$, a lower shrinkage from $700^{\circ} \mathrm{C}$ to $1100^{\circ} \mathrm{C}$ and a lower electric resistivity. The results indicated that the paste which consists of an pulverized $\mathrm{Ag}-\mathrm{Pd}$ alloy powder was superior in performance to the other two pastes for an internal electrode material of multilayer ceramic device. KEY WORDS

Silver-Palladium, Alloy powders, Internal electrode, Paste, Multilayer ceramic devices

\section{Introduction}

At present, silver-palladium (Ag-Pd) coprecipitated powders are the materials often used for internal electrodes of multilayered ceramic capacitors (MLC) and multilayered piezoelectric actuators. Conventional Ag-Pd coprecipitated powder is easily oxidized during resin removal process; the oxidized powder is easily reduced and rapidly release oxygen around the sintering temperature of ceramics. It has been reported that these redox reaction cause a delamination, an expansion and cracks of electrode near boundary regions between electrode and ceramic capacitor. And the following problems are occurred by the heat treatments: silver oxide $\left(\mathrm{Ag}_{2} \mathrm{O}\right)$ and palladium oxide ( $\left.\mathrm{PdO}\right)$ formed during the resinremoval process react with lead $(\mathrm{Pb})$ in dielectric materials and degrade the dielectric characteristics of the ceramics ${ }^{1-11}$. For example, Ling et al. ${ }^{1)}$ reported that silver (Ag) is diffused into magnesium led niobate (PMN) from an internal electrode (Ag-Pd) of the MLC after $10 \mathrm{~h}$ of annealing at $800^{\circ} \mathrm{C}$ and is diffused over a distance of approximately $5 \mu \mathrm{m}$. Slinkina et al. ${ }^{2}$ ) also reported that $\mathrm{Ag}$ has a high diffusion coefficient and is diffused into ceramics composed of $\mathrm{Pb}_{0.95} \mathrm{Sr}_{0.06}\left(\mathrm{Zr}_{0.53} \mathrm{Ti}_{0.47}\right) \mathrm{O}_{3}+1 \mathrm{~mol} \% \mathrm{Nb}_{2} \mathrm{O}_{5}$ over a distance more than $100 \mu \mathrm{m}$. Chu ${ }^{3}$ et al. similarly demonstrated that diffusion of $\mathrm{Ag}$ promoted particle growth of $\mathrm{Ag}$, which increased the maximum values of the dielectric constant and dielectric loss, and deteriorates insulation resistance of dielectric materials. However, there have been very few reports about the influence of $\mathrm{Ag}$ diffusion into dielectric material on the reliability of capacitor performance. Maher et al. ${ }^{4)}$ conducted accelerated lifetime tests for lowtemperature-sintered $\mathrm{BaTiO}_{3}-\mathrm{MLCs}$ with internal electrodes composed of $\mathrm{Ag}-\mathrm{Pd}(70-30$, wt $\%)$ or $\mathrm{Au}-\mathrm{Pd}-\mathrm{Pt}$ (60-20-20, wt\%). They did not, however, clarify the influence of $\mathrm{Ag}$ diffusion on dielctrics. Recently-developed large capacitance MLCs have a dielectric material with thickness of $10 \mu \mathrm{m}$ or the less; therefore, diffusion of $\mathrm{Ag}$ into the dielectric layers from an internal electrode has become an increasingly important concern ${ }^{7-9}$. Kanai et al. ${ }^{10,11)}$ compared the temperature characteristics of the dielectric constants of MLCs to those of disk samples, both of which has dielectric layer with $13 \mu \mathrm{m}$ in thickness and Ag-Pd (70-30, wt \%) internal electrode. And they found that dielectric constants of the MLCs increased by $8 \%$ and the Curie point (Tc) decreased by $5^{\circ} \mathrm{C}$ compared to disk samples. The results suggested that $\mathrm{Ag}$ diffusion possibly deteriorates insulation resistance.

Recently, it was found that alloy powders used for electrode materials effectively prevent a deterioration of 
insulation resistance. And methods to synthesize ultrafine alloy powders for internal electrode have been actively investigated $\mathrm{d}^{12-19}$.

In this study, we focused on a wet chemical method for synthesis of ultrafine metal powder, which can be applied to mass production at low cost. We investigated the temperature and the time dependences of alloy formation by heat treatment of coprecipitated powders. And the investigation extended to the clearness of relationship between powder morphology and packing density of electrode films. The relationship needs to investigate for the production of high-capacity MLC. In addition, the electrical characteristics of electrode films were investigated for a paste consisting of pulverized Ag-Pd alloy powder by comparing with the pastes prepared from conventional coprecipitated powder and from unpulverized alloy powder.

\section{Experimental methods}

Coprecipitated powders with composition of $70 \% \mathrm{Ag} /$ 30\% Pd (hereafter abbreviated as Ag-Pd(70-30)) and 30\% $\mathrm{Ag} / 70 \% \mathrm{Pd}(\mathrm{Ag}-\mathrm{Pd}(30-70))$ were used as starting material. Both powders were synthesized from silver nitrate and palladium nitrate as metal seeds by a wet chemical reduction method with hydrazine anhydride as reducing agent. With respect to alloy formation, temperature dependence of $\mathrm{Ag}$ $\mathrm{Pd}$ coprecipitated powders was investigated at heating temperatures from 300 to $500^{\circ} \mathrm{C}$ under an inert atmosphere; in addition, a time dependence of heat-treatment was investigated from $1 \mathrm{~h}$ to $5 \mathrm{~h}$ at the same temperature range. With respect to pulverization of agglomerated powders, a degree of pulverization of agglomerated $\mathrm{Ag}-\mathrm{Pd}(70-30)$ or Ag-Pd(30-70) powders, both of which are mechanically pulverized by either a dry or a wet method, was investigated by using a scanning electron microscope (SEM) and by measurements of the mean particle size and particle size distribution. A formation of Ag-Pd alloy was confirmed by X-ray diffractometry using $\mathrm{CuK} \alpha$ (XRD; Rint-200, Rigaku Electrics). A degree of agglomeration before and after the heat treatment for alloy formation was evaluated from a measurement of particle size distributions of alloy powders by using a laser-deflection particle-sizedistribution meter (Microtrack, HRA100 type, Nikki Sou, Co., Ltd.). Oxidation behavior of alloy powders was investigated by using thermogravimetric differential thermal analyzer (TG-DTA; Thermoflex, Rigaku Electrics). The properties of alloy powders were evaluated from the tapping density and the specific surface area of the powders determined by the BET method.

Pastes for electrode film were prepared as follows: each of the metal powder was mixed with terpineol solution containing ethyl cellulose as the binder. The resulting mixture was subjected to conventional mixing by a highspeed vibration mixer (MKR-300, Daiken Chemical Ind. Co., Ltd.). In order to evaluate properties of the pastes, the pastes were tape-casted to films for green density and shrinkage measurements, and also screen-printed on alumina substrate to form $\mathrm{Ag}-\mathrm{Pd}$ electrode film for resistivity and surface microstructure measurements. A shrinkage of the casted films was measured after the sintering at a temperature range from $400^{\circ} \mathrm{C}$ to $1100^{\circ} \mathrm{C}$. A microstructure of surface of electrode film was observed by SEM (JSM-6100, Nihon Electronics) measurement. An electric resistivity of the film was also measured. A composition of the electrode film and a distribution of $\mathrm{Ag}$ and Pd in the film were analyzed by EPMA.

\section{Results and discussion}

3.1 Dependence of alloy formation on heating temperature and time

Fig. 1 shows XRD patterns of $\mathrm{Ag}-\mathrm{Pd}(70-30)$ coprecipitated powders fired at temperatures from $300^{\circ} \mathrm{C}$ to $500^{\circ} \mathrm{C}$ for various sintering times in inert atmosphere. Fig. 2 shows

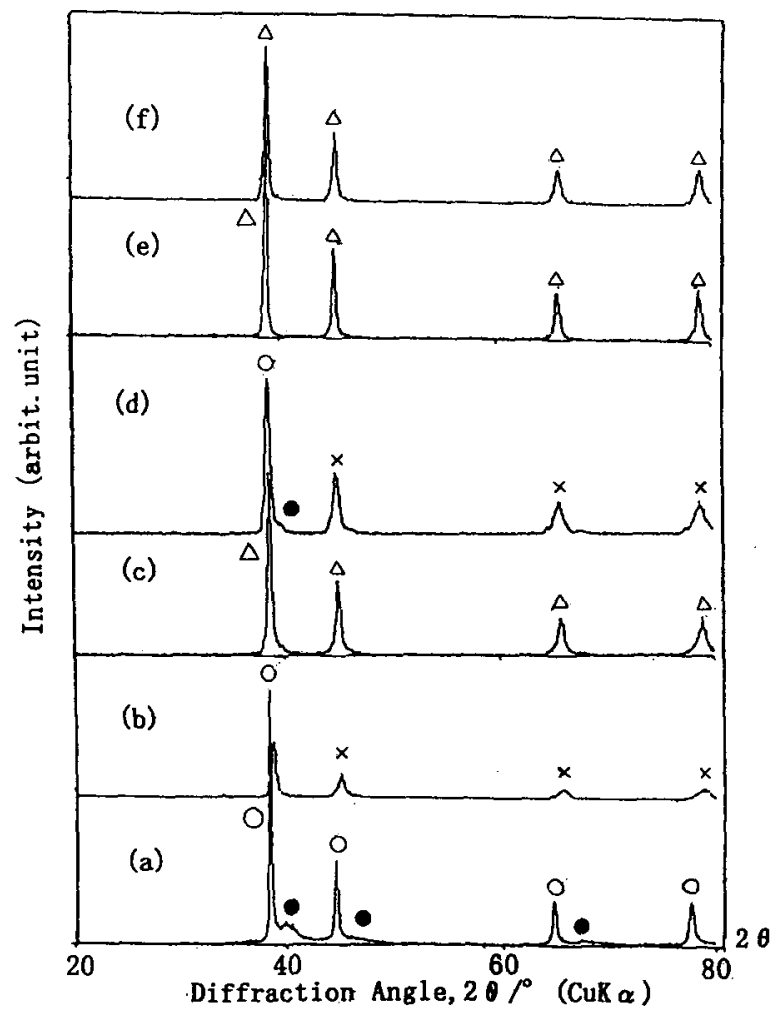

Fig.1 X-ray diffraction patterns of Ag-Pd powders with various heating temperatures and times. (a) $\mathrm{Ag}-\mathrm{Pd}(70-30)$ coprecipitated powders, (b) $300^{\circ} \mathrm{C}-1 \mathrm{hr}$, (c) $300^{\circ} \mathrm{C}-5 \mathrm{hr}$, (d) $350^{\circ} \mathrm{C}-1 \mathrm{hr}$, (e) $350^{\circ} \mathrm{C}-5 \mathrm{hr}$, (f) $400^{\circ} \mathrm{C}-1 \mathrm{hr}$.

$O: \mathrm{Ag}, \mathrm{O}: \mathrm{Pd}, \mathrm{X}:$ Non Alloying, $\triangle:$ Alloying. 
XRD patterns of $\mathrm{Ag}-\mathrm{Pd}(30-70)$ coprecipitated powders subjected to the same heat treatment.

As shown in Fig. 1, the Ag-Pd(70-30) coprecipitated powder formed an alloy at $300^{\circ} \mathrm{C}$ for $5 \mathrm{~h}$. When shortened the sintering time, alloy formation is not complete even at $350^{\circ} \mathrm{C}$.

As shown in Fig. 2, the Ag-Pd(30-70) coprecipitated powder formed an alloy at $500^{\circ} \mathrm{C}$ for $1 \mathrm{~h}$. An increase in the $\mathrm{Pd}$ content in the powder need higher temperature for alloy formation. These results indicated that paste with higher $\mathrm{Ag}$ content was affected remarkably by sintering time rather than sintering temperature for alloy formation; the paste with higher Pd content, however, was affected strongly by sintering temperature rather than sintering time. This may be due to the ease diffusion of Ag into Pd during the alloy formation.

\subsection{Pulverization of agglomerated particles}

Agglomerated particles were pulverized into primary particles by application of mechanical force either of the dry or the wet methods. As is well known that fine metal powders of approximately $1 \mu \mathrm{m}$ in particle size or the less agglomerate strongly under dry conditions and behave as if they were bulk powders. Strongly reagglomerated Particles were often observed after drying of metal powder dispersed in a solution. In this study, the following procedure was used to prevent pulverized powder from a reagglomeration: organic compounds which react directly with metal powder were added to the slurry made of

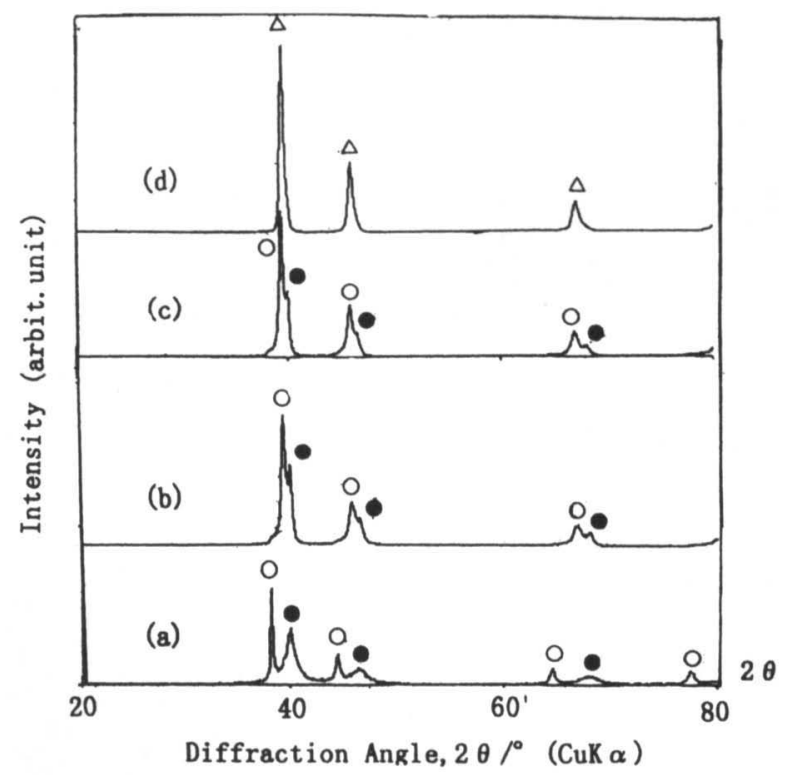

Fig.2 X-ray diffraction patterns of $\mathrm{Ag}-\mathrm{Pd}$ powders with various heating temperatures and times. (a) $\mathrm{Ag}-\mathrm{Pd}(30-70)$ coprecipitated powders, (b) $400^{\circ} \mathrm{C}-3 \mathrm{hr}$, (c) $400^{\circ} \mathrm{C}-5 \mathrm{hr}$, (d) $500^{\circ} \mathrm{C}-1 \mathrm{hr}$.

$\mathrm{O}: \mathrm{Ag}, \boldsymbol{O}: \mathrm{Pd}, \times:$ Non Alloying, $\Delta:$ Alloying. agglomerated alloy powder, then a strong mechanical shearing force was applied to the slurry to pulverize the agglomerated particles. And a mechano-chemical reaction was simultaneously occured on the surface of the newly generated alloy particles to form a self-organizing film with the organic compounds. Thus a reagglomeration of powder was controlled by this reaction.

Fig. 3 shows SEM images of agglomerated powder in a slurry consisting of Ag-Pd(70-30) coprecipitated powder, which subjected to no heat treatment nor no pulverized treatment, and alloy powder pulverized by the mechanical dispersion and pulverization method. Fig. 4 shows particle size distribution of the coprecipitated powder, unpulverized alloy powder and pulverized alloy powder. As shown in
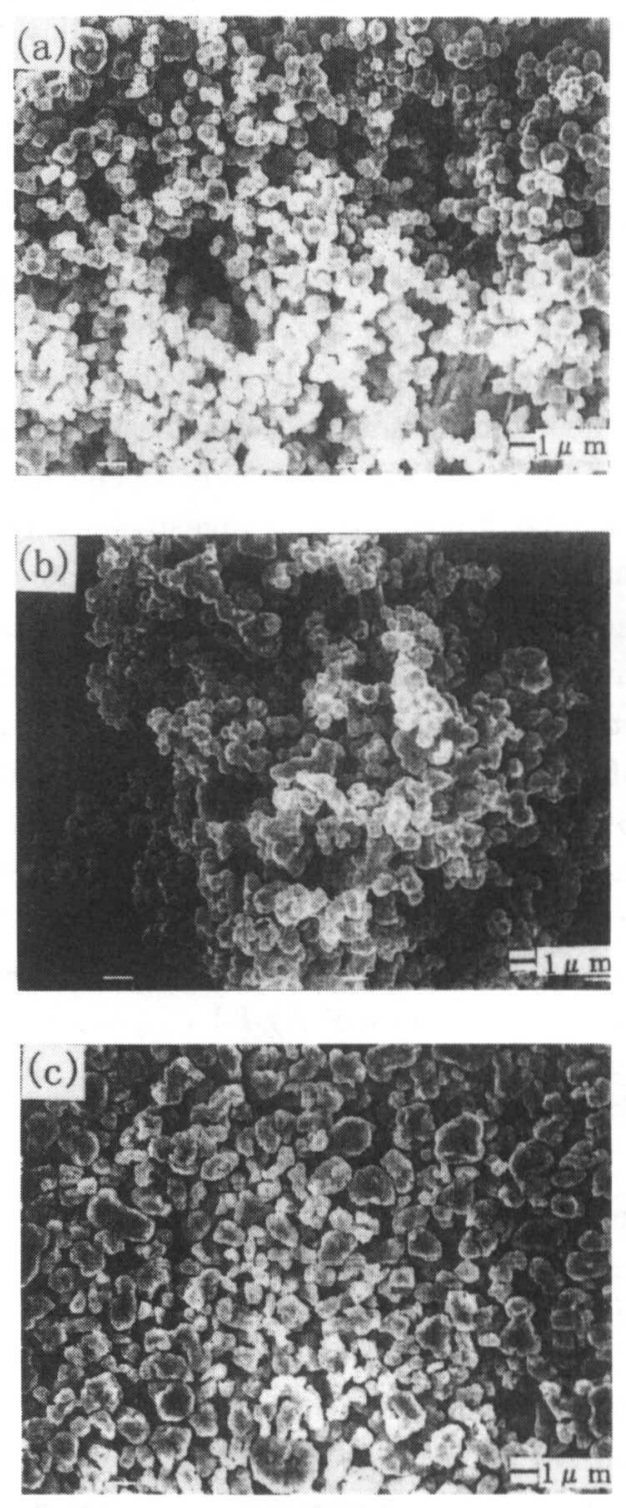

Fig.3 SEM photographs of various Ag-Pd powders. (a) $\mathrm{Ag}-\mathrm{Pd}(70-30)$ coprecipitated powders. (b) Ag-Pd(70-30) non-pulverized alloy powders. (c) Ag-Pd(70-30) pulverized alloy powders. 
Figs. 3 and 4, agglomerated particles shaped like a bunch of grapes with $10 \mu \mathrm{m}$ in diameter or the larger were sequentially pulverized into primary particles by the mechanical dispersion and pulverization method. In addition, the results of particle size distribution (Fig.4) showed that reagglomeration of the pulverized powder in slurry during drying process was suppressed by the presence of the organic self-forming film.

\subsection{Powder properties of alloy particles}

Fig. 5 shows the TG-DTA curves of Ag-Pd(30-70) coprecipitated and Ag-Pd(30-70) alloy powders. The TG curves in Fig. 5 (a) showed that an oxidation gradually occured around $200^{\circ} \mathrm{C}$ for coprecipitated powder, while the

(a)

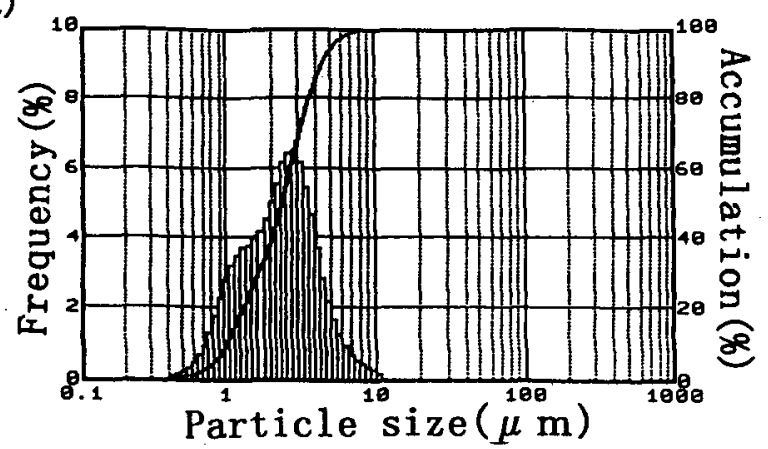

(b)

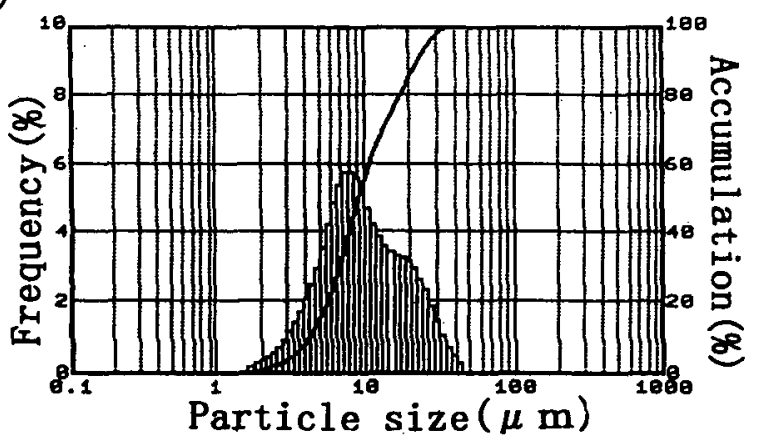

(c)

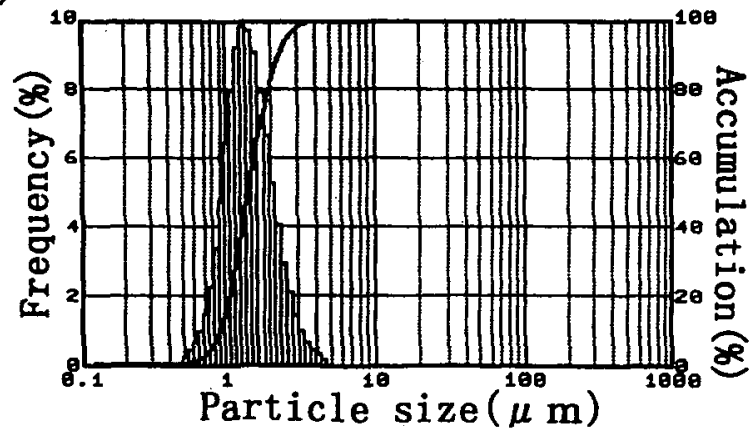

Fig.4 A particle size distribution measured by Microtrac laser particle size analyzer.

(a) Ag-Pd(70-30) coprecipitated powders.

(b) $\mathrm{Ag}-\mathrm{Pd}(70-30)$ non-pulverized alloy powders.

(c) $\mathrm{Ag}-\mathrm{Pd}(70-30)$ pulverized alloy powders. alloy powder began to be oxidized rapidly at approximately $400^{\circ} \mathrm{C}$. The results suggested that thermal resistance of powder was improved by alloy formation in the powder. Fig.5 (b) showed DTA curves. Exothermic peaks due to oxidation of $\mathrm{Ag}$ and Pd were observed at approximately $200^{\circ} \mathrm{C}$ and $470^{\circ} \mathrm{C}$, respectively, and endothermic peak due to reduction of $\mathrm{Pd}$ oxide around $800^{\circ} \mathrm{C}$ for coprecipitated powders. In contrast, exothermic peak due to oxidation of alloy was observed at approximately $550^{\circ} \mathrm{C}$ and a relatively small endothermic peak due to reduction of alloy oxide around $800^{\circ} \mathrm{C}$ for the alloy powders. The results indicated that the alloy powders are superior in oxidation resistance to the coprecipitated powders. Table 1 shows the specific surface area and tap density of three different powders; Ag-Pd coprecipitated powder, alloy powder without pulverization and alloy powder with pulverization treatment. The specific surface area of pulverized alloy
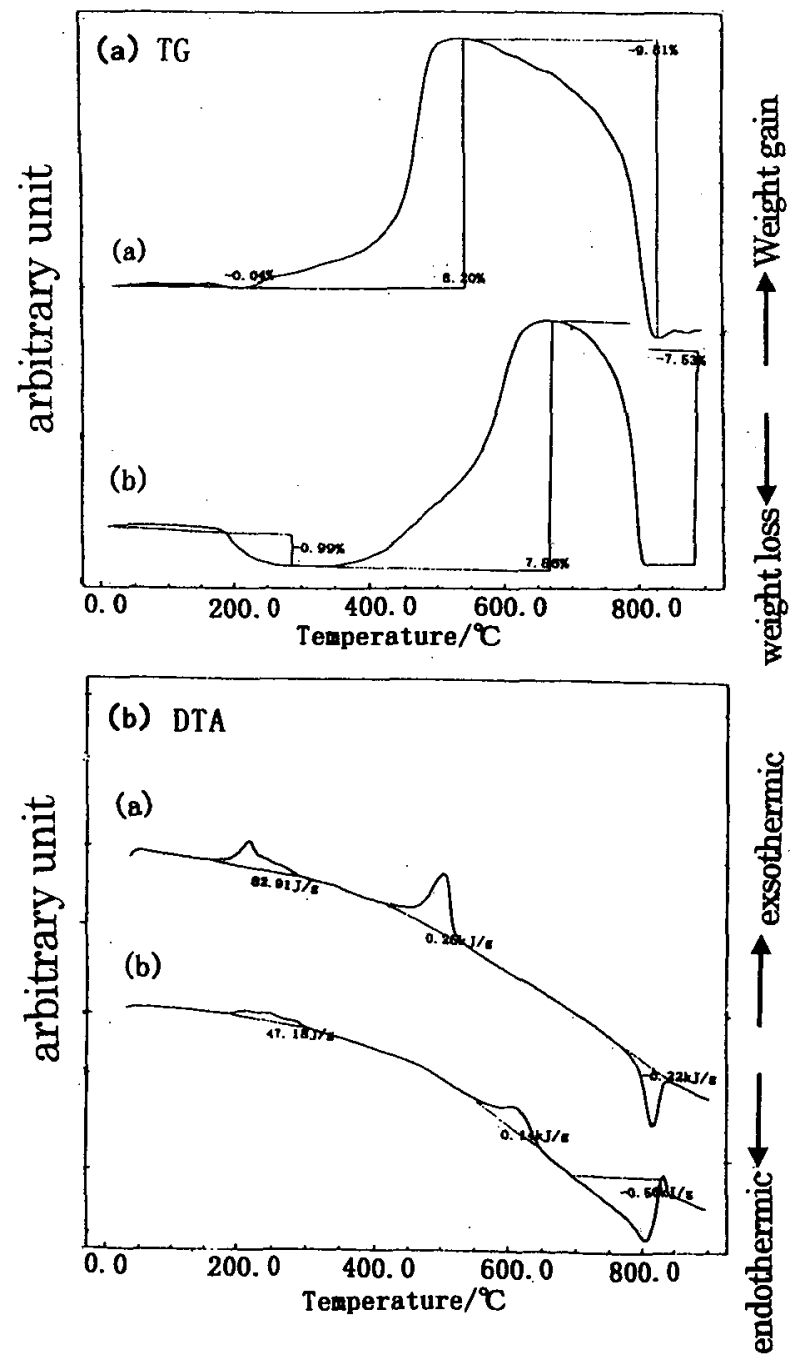

Fig.5 TG-DTA curve of Ag-Pd powders.

(a) Ag-Pd(30-70) coprecipitated powders.

(b) Ag-Pd (30-70) alloy powders. 
powder was smaller than those of the coprecipitated powder and alloy powder without pulverization. The pulverized alloy powder had higher tapping density than other two. Those results may come from a formation of dense and smooth surface of the pulverized alloy particles because of the melting of the surface of the particles as observed in SEM measurements, and of a formation of monodispersed particles from agglomerate by pulverization.

3.4 Characteristics of paste prepared from alloy powder

(1) Influence of powder morphology on green density of casted films

Pastes for internal electrodes used in MLCs and multilayered piezoelectric actuators should essentially be composed of homogenous monodispersed primary particles without agglomeration. The degree of monodispersity is evaluated by measuring the packing density (16) of the film made by tape casting. Designating the green density as $\rho \mathrm{g}$, the dry density of the powder as $\rho \mathrm{d}$, and the mass content of the powder as $\mathrm{Xd}$, the packing density $P$ is given as equation (1).

Table 1 Densities of Ag-Pd powders.

(a) Ag-Pd(70-30) coprecipitated powders.

(b) Ag-Pd (70-30) non-pulverized alloy powders.

(c) Ag-Pd (70-30) pulverized alloy powders.

\begin{tabular}{lccc}
$\begin{array}{l}\text { Sample } \\
\text { namo }\end{array}$ & $\begin{array}{l}\text { Average particle } \\
\text { size }(\mu)\end{array}$ & $\begin{array}{l}\text { Specific surface } \\
\text { arga }\left(\mathbf{m}^{2} \mathbf{g}^{-1}\right)\end{array}$ & $\begin{array}{l}\text { Tap density } \\
\left(\mathrm{gcm}^{-3}\right)\end{array}$ \\
\hline (a) & 2.34 & 0.99 & 1.90 \\
(b) & 9.13 & 1.53 & 0.92 \\
(c) & 1.40 & 1.13 & 4.05 \\
\hline
\end{tabular}

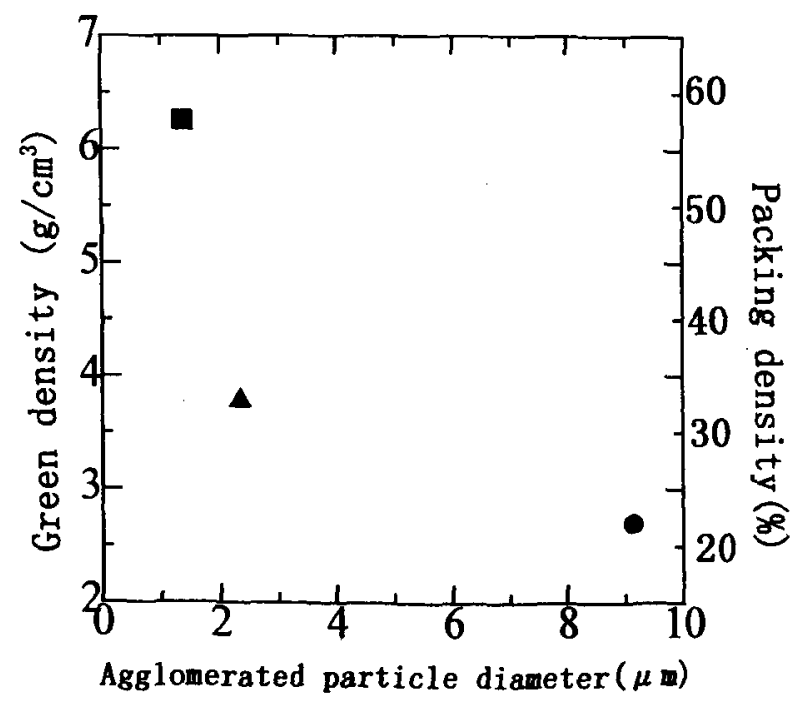

Fig.6 Relationship among agglomerated particle diameter, green density and packing density.

A: Ag-Pd (70-30) coprecipitated powders.

Ag-Pd(70-30) non-pulverized alloy powders.

Ag-Pd(70-30) pulverized alloy powders.

$$
\mathrm{P}=\rho \mathrm{g} \cdot \mathrm{Xd} / \rho \mathrm{d}
$$

Fig. 6 shows the relationship between agglomerated particle size and green density of the film, and the one between agglomerated particle size and packing density obtained from eq.(1).

As shown in Fig.6, the green density of the film made of the coprecipitated powder was $3.8 \mathrm{~g} / \mathrm{cm}^{3}$, and that of the film of the unpulverized alloy powder was $2.7 \mathrm{~g} / \mathrm{cm}^{3}$, whereas that of the film of the pulverized alloy powder was greatly improved to be $6.2 \mathrm{~g} / \mathrm{cm}^{3}$. This result indicated that agglomerated alloy powder due to thermal treatment was almost pulverized to primary particles, which resulted in significant increase in the green density of casted film. It could also mention that dispersibility of the pulverized alloy powder was improved remarkably. Furthermore, since the packing density of the film of the pulverized alloy powder was $57 \%$, which was higher than that of the film of unpulverized powder (25\%), the Ag-Pd pulverized alloy powder is almost regarded as monodispersed powder.

(2) Relationship between sintering shrinkage and powder morphology

Three types of pastes were prepared from $\mathrm{Ag}-\mathrm{Pd}$ coprecipitated powder, unpulverized alloy powder and pulverized alloy powder. These pastes were tape-casted to film and sintered at a temperature range from $400^{\circ} \mathrm{C}$ to $1100^{\circ} \mathrm{C}$. A shrinkage of the film was measured after the sinterings. As shown in Fig. 7, the film made of Ag-Pd coprecipitated powder showed a high expansion as $6.1 \%$ at $400{ }^{\circ} \mathrm{C}$ due to oxidation, and finally showed $29.3 \%$ in

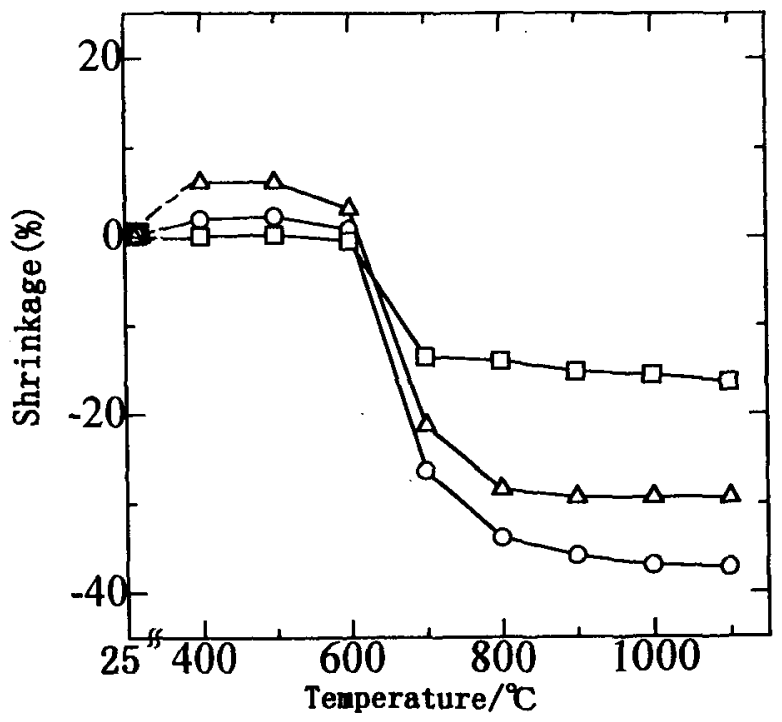

Fig.7 Relationship between firing temperature and shrinkage. $\triangle:$ Ag-Pd (70-30) coprecipitated powders. $0: \mathrm{Ag}-\mathrm{Pd}(70-30)$ non-pulverized alloy powders. $\square: \mathrm{Ag}-\mathrm{Pd}(70-30)$ pulverized alloy powders. 
shrinkage after the sintering at $1100^{\circ} \mathrm{C}$. In contrast, the film made of the pulverized alloy powder showed a lower expansion as $0.21 \%$ at $400^{\circ} \mathrm{C}$ due to oxidation, and $16.38 \%$ in shrinkage after the sintering at $1100^{\circ} \mathrm{C}$, which could be predicted from the higher packing density of pulverized alloy film. A shrinkage of the film of the pulverized alloy powder almost reached a constant value at $700^{\circ} \mathrm{C}$, and did not change up to $1100^{\circ} \mathrm{C}$. This tendency is different from that of the film made of $\mathrm{Ag}-\mathrm{Pd}$ coprecipitated powder at temperature range from $800^{\circ} \mathrm{C}$ to $900^{\circ} \mathrm{C}$. From these results, a sintering temperature for the electrode film made of pulverized alloy powder might be lowered by $100^{\circ} \mathrm{C}-$ $200^{\circ} \mathrm{C}$ than the film of coprecipitated powder, which indicated that the former powder has superior in view of lower-sintering characteristics. An expansion of the film due to oxidation was similar for unpulverized alloy powder and pulverized alloy powder. However, since the packing density of the film of unpulverized alloy powder was lower because of containing agglomerate particles, the final shrinkage of the film of unpulverized alloy powder was fairly as high as $37.1 \%$. Thus, an expansion of the film sintered at $600^{\circ} \mathrm{C}$ or lower is mainly affected by oxidation, and a shrinkage of film sintered at $600^{\circ} \mathrm{C}$ or higher is mainly affected by the dispersibility of the powder.

(3) Relationship between electric resistivity and powder morphology

An electric resistivity of three types of electrode films was measured at room temperature and shown in Fig. 8. There was no difference in the electric resistivity for the films made of coprecipitated powder and pulverized alloy powder sintered at temperatures between $700^{\circ} \mathrm{C}$ and $1000^{\circ} \mathrm{C}$. However, an electric resistivity of the film of coprecipitated powder was remarkably decreased from $110 \mu \Omega \mathrm{cm}$ to $15 \mu \Omega \mathrm{cm}$ as the sintering temperature increased from $400^{\circ} \mathrm{C}$ to $700^{\circ} \mathrm{C}$. A large change in electric resistivity was clearly observed for the film of coprecipitated powder sintered at resin removal temperature range. And for the sintering temperature above $1000^{\circ} \mathrm{C}$, a resistivity was increased from $5 \mu \Omega \mathrm{cm}$ (sintered at $1000^{\circ} \mathrm{C}$ ) to $8 \mu \Omega \mathrm{cm}$ (at $1100^{\circ} \mathrm{C}$ ). Such small increase in resistivity of film made of coprecipitated powder was considered to be due to particle growth as shown in the SEM observation. This phenomenon is also observed in the film made of unpulverized alloy powder; an electric resistivity was increased from $15 \mu \Omega \mathrm{cm}$ (sintered at $1000^{\circ} \mathrm{C}$ ) to $18 \mu \Omega \mathrm{cm}$ (at $1100^{\circ} \mathrm{C}$ ). And much larger changes in electric resistivity were observed at sintering temperature between $400^{\circ} \mathrm{C}$ and $700^{\circ} \mathrm{C}$. In contrast, the film made of pulverized alloy powder showed a small decrease in electric resistivity from
$18 \mu \Omega \mathrm{cm}$ to $5 \mu \Omega \mathrm{cm}$ as the sintering temperature increased from $400^{\circ} \mathrm{C}$ to $1000^{\circ} \mathrm{C}$. An electric resistivity of the film made of pulverized alloy powder sintered at $1000^{\circ} \mathrm{C}$ and $1100^{\circ} \mathrm{C}$ was almost the same value as that of bulk Ag-Pd $(70-30)(3-4 \mu \Omega \mathrm{cm})$. The results came from the reason that an anomalous particle growth was suppressed in the film of pulverized alloy powder because of pulverization of agglomerated particles.

Problems associated with the sintering of MLCs, such as delamination, expansion, cracks, broken electrodes and short circuits, are triggered by rapid sintering of $\mathrm{Ag}-\mathrm{Pd}$ electrode. The results mentioned above demonstrate that dispersibility of alloy particles in the paste is a very important factor for electrode sintering.

(4) Surface microstructure of sintered electrode films

Surface microstructure of three types of films made by tape casting was observed by SEM measurements and shown in Fig.9. The film made of pulverized alloy powder was highly densified at $800^{\circ} \mathrm{C}$ and had facets on the surface of the film. In contrast, striped patterns rather than facets were observed on the surface of the film made of coprecipitated powder. This phenomenon observed in the film of coprecipitated powder might come from the reason that independent particle growths of $\mathrm{Ag}$ and $\mathrm{Pd}$ were proceeded simultaneously with formation of Ag-Pd alloy during heat treatment. Fig. 10 showed the distribution of $\mathrm{Ag}$ and $\mathrm{Pd}$ in the film sintered at $1100^{\circ} \mathrm{C}$. $\mathrm{Ag}$ and $\mathrm{Pd}$

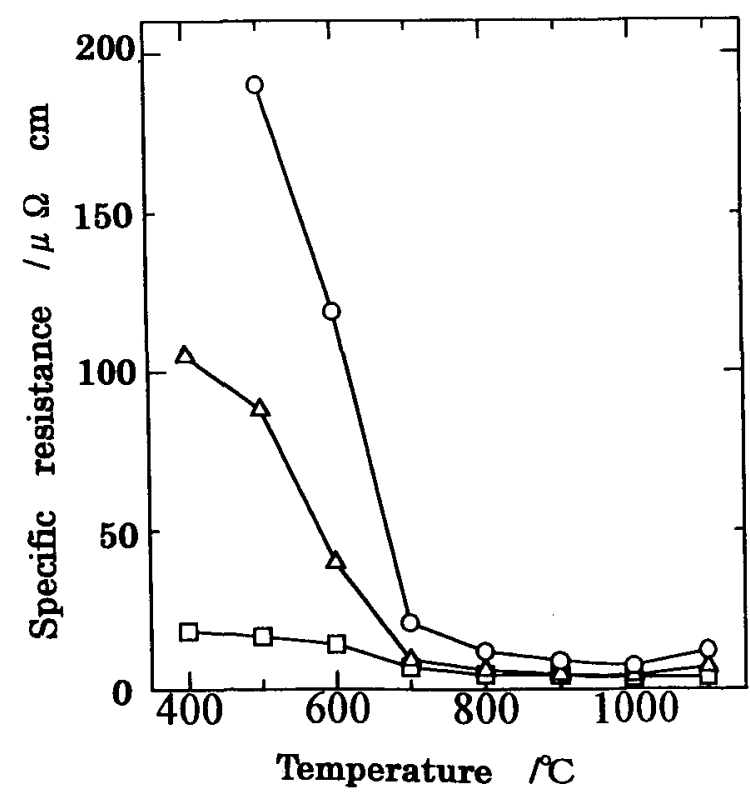

Fig.8 Relationship between firing temperature and electric resistibity of the films made of various $\mathrm{Ag}-\mathrm{Pd}$ powders.

$\triangle:$ Ag-Pd(70-30) coprecipitated powders.

$\mathrm{O}: \mathrm{Ag}-\mathrm{Pd}(70-30)$ non-pulverized alloy powders.

$\square: \mathrm{Ag}-\mathrm{Pd}(70-30)$ pulverized alloy powders. 
(1)

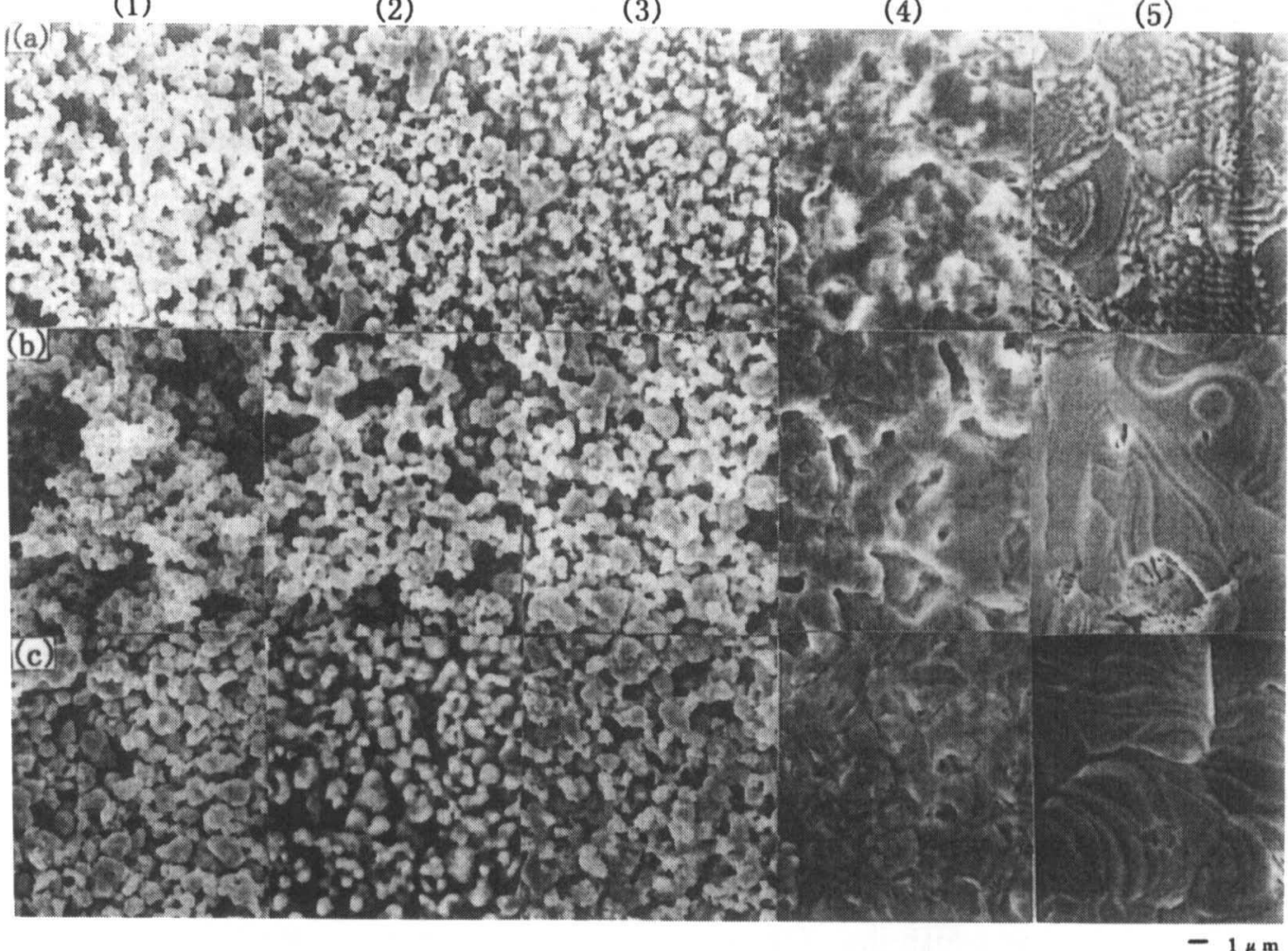

Fig.9 SEM photographs of surface of films made of various Ag-Pd powders.

(a) Ag-Pd(70-30) coprecipitated powders.

(b) Ag-Pd(70-30) non-pulverized alloy powders.

(c) Ag-Pd(70-30) pulverized alloy powders.

(1) $\mathrm{Ag}-\mathrm{Pd}$ powders before firing, (2) fired at $400^{\circ} \mathrm{C}$, (3) fired at $600^{\circ} \mathrm{C}$, (4) fired at $800^{\circ} \mathrm{C}$, (5) fired at $1100^{\circ} \mathrm{C}$

distributed inhomogeneously in the film made of coprecipitated powder. This is probably lead to an inhomogeneous alloy formation in the film because alloy formed during the heat treatment for the films made of coprecipitated powder. In contrast, an macroscopicaly homogeneous composition is observed in the film made of pulverized alloy powder. However, homogeneous distribution of $\mathrm{Ag}$ and $\mathrm{Pd}$ in microscopic order was not noted in the SEM images. A dispersibility of powder was much improved in the films made of pulverized alloy powder rather than coprecipitated powder.

In order to study homogeneity of the alloy powder, we calculated the weight ratio of Pd to the entire weight by removing the element identified as Pd from the EPMA image. As a result, the relative amount of the Ag-rich alloy phase was determined to be $85.7 \%$, and that of Pd-rich alloy phase was $14.3 \%$. It is said that $\mathrm{Ag}-\mathrm{Pd}$ alloy was not formed with complete homogeneity, but had a composition of at least $15.7 \%$ of the Pd exist. Even if an alloy was confirmed to have complete homogeneity by XRD analysis, $\mathrm{Ag}$-rich and Pd-rich phases might be coexisted. Since alloyformation experiment in the present study was carried out as low temperature as $300^{\circ} \mathrm{C}$ for $5 \mathrm{~h}$, it is not expected that $\mathrm{Ag}$ and $\mathrm{Pd}$ form completely homogeneous alloy. Macroscopically homogeneous alloys were finally formed in the both films made of coprecipitated powder and pulverized alloy powder by heat treatment at $1100^{\circ} \mathrm{C}$, but locally segregated $\mathrm{Ag}$ might exist in the films of coprecipitated powder. These segregated $\mathrm{Ag}$ and $\mathrm{Ag}$ in incomplete $\mathrm{Ag}-\mathrm{Pd}$ alloy may react with $\mathrm{Pb}$ components in PMNs and PZTs, and results in a deterioration of the dielectric characteristics of the dielectric materials.

A Surface of the electrode film formed by screen printing needs to be flat and pinholeless. A surface roughness of the films made of Ag-Pd(70-30) coprecipitated powder and pulverized alloy powder was measured. A film made of coprecipitated powder had a rather convex-concave surface and a pretty large surface roughness as $0.16 \mu \mathrm{m} \mathrm{Ra}$. In contrast, the film made of pulverized alloy powder had fairly flat surface with surface roughness of $0.13 \mu \mathrm{m} \mathrm{Ra}$.

\section{Conclusion}

Physical and electrical properties of three types of $\mathrm{Ag}$ Pd electrode films, which consist of different metal fine 
(a)

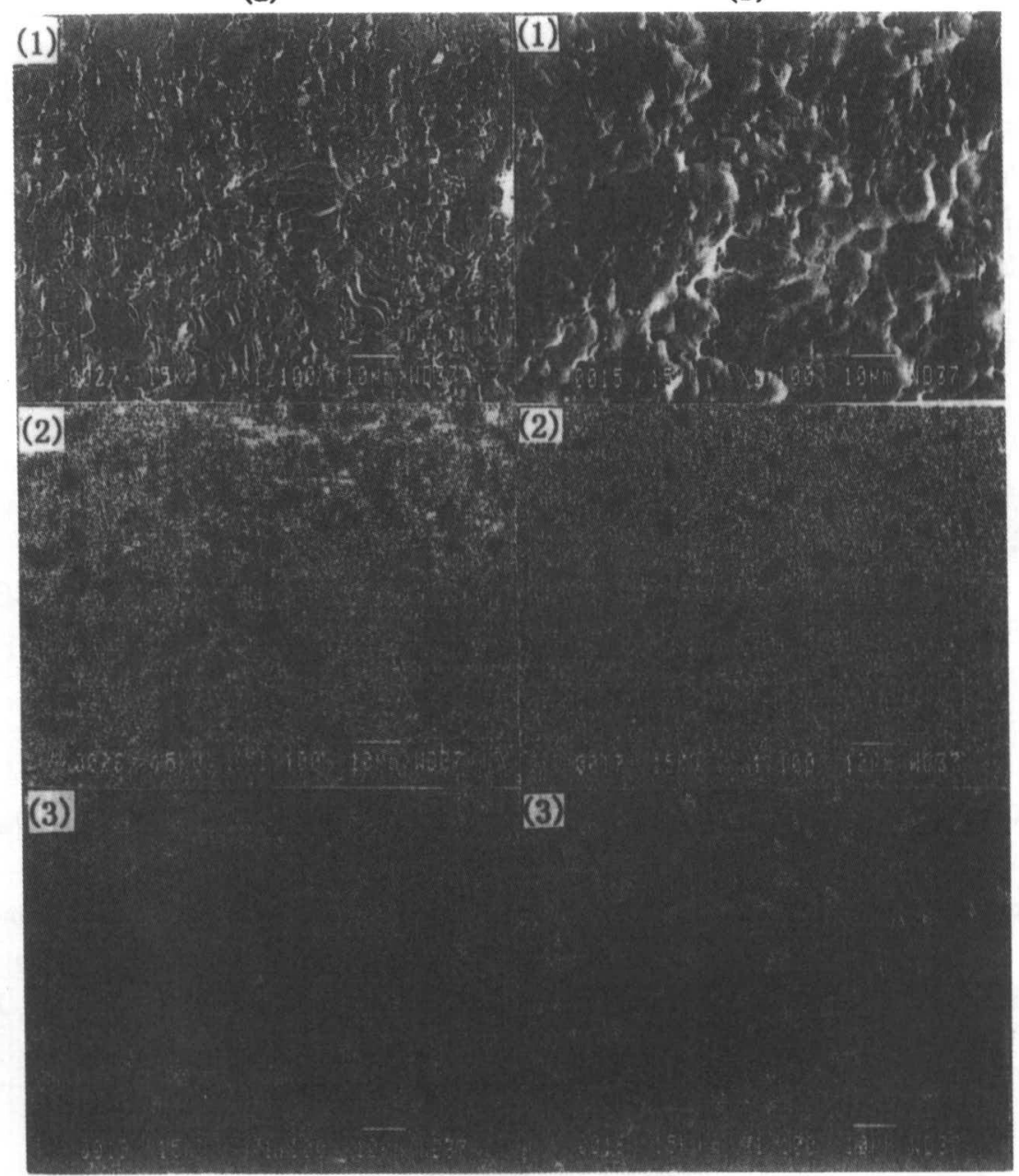

Fig.10 EPMA image of surface of films made of coprecipitated powder and pulverized alloy powder fired at $1100^{\circ} \mathrm{C}$.

(1) Ag-Pd(70-30) coprecipitated powders.

(2) Ag-Pd(70-30) pulverized alloy powders.

powders have been studied. And the following conclusions are obtained.

(1) Ag-Pd (70-30) coprecipitated powder (i.e., containing excess $\mathrm{Ag}$ ) was formed into alloy by heating at $300^{\circ} \mathrm{C}$ for 5h. And Ag-Pd(30-70) powder (containing excess Pd) was formed into alloy at $500^{\circ} \mathrm{C}$ for $1 \mathrm{~h}$.

(2) The alloy powder synthesized in this study showed higher oxidation and thermal resistances than the coprecipitated powder

(3) The film made of pulverized alloy powder showed higher green density than the films made of coprecipitated powder and unpulverized alloy powder.

(4) Electrode Film made of pulverized alloy powder showed smaller shrinkage than the films made of coprecipitated powder and unpulverized alloy powder for the sinterings at temperature up to $1100^{\circ} \mathrm{C}$.

(5) An electric resistivity of electrode film made of pulverized alloy powder was $5 \mu \Omega \mathrm{cm}$ which is almost same value as that of bulk $\mathrm{Ag}-\mathrm{Pd}(70-30)$.

(6) An electrode film made of pulverized alloy powder had fairly flat surface with surface roughness of $0.13 \mu \mathrm{m} \mathrm{Ra}$.

\section{Reference}

1) H.C.Ling: "Diffusion of sputtered Vanadium, Nickel, and Silver in Lead Magnesium Niobate Ceramics", J. Am. Ceram. Soc., 72(1989)770-774.

2) M.V.Slinkina, G.I.Dontsov and V.H.Zhukovsky: "Silver Diffusion at Metallization of Piezoelerctrics", Materials Science Forum, 62-64(1990)363-364.

3) M.H.Chu and C.E.Hodgkings: "Ceramic and Metal Oxide Interaction in Multilayer Ceramic Capacitors", Advanced in Ceramics, 19(1986)203-217.

4) G.H.Maher, T.I.Prokopowicz and V.Bheemineni: "Properties of X7R MLC Capacitors Containing 70Ag/30Pd or $60 \mathrm{Au} / 20 \mathrm{Pd} / 20 \mathrm{Pt}$ Internal Electrode Composition", Proc. of 1992 Capacitor and Resistor 
Tech. Sympo., (1992)23-28.

5) G.H.Maher: "Effect of Silver Doping on the Physical and electrical Properties of PLZT Ceramics", J. Am. Ceram. Soc., 66(1983)408-413.

6) K.V.R.Murty, S.N.Murty, K.C.Mouli and A.Bhanumathi: "Domain Orientation and Piezoelectric Properties of Doped PMN-PZT Ceramics", Proc. of IEEE 1992 Int '] Sympo.on Applications of Ferroelectrics, (1992)144147.

7) S.Saito, A.Ochi, K.Utsumi, M.Yonezawa, J.Morisita and T.Yoshimoto: "A New Dielectric Ceramics Material for Capacitors with High Specific Capacitance", IMC 1988 Proc., (1988)211-218.

8) G.H.Maher: "MLC Capacitors with 6 microns active dielectric and X7R Electrical characteristics", Ceramic Transactions, 11(1990)429-435.

9) J.Borzych and H.Harada: "Advanced in High CV Multilayer Ceramics Chip Capacitors", Proc. 41st ECTC, (1991)442-445.

10) H.Kanai, O.Furukawa, S.Nakamura and Y.Yamashita: "Effect of Stoichiometry on the Dielectric Properties and the life Performance of $\left(\mathrm{Pb}_{0.875} \mathrm{Ba}_{0.125}\right)\left[\left(\mathrm{Mg}_{1 / 3}\right.\right.$ $\left.\left.\mathrm{Nb}_{2 / 3}\right)_{0.5}\left(\mathrm{Zr}_{1 / 3} \mathrm{Nb}_{2 / 3}\right)_{0.3} \mathrm{Ti}_{0.2}\right] \mathrm{O}_{3}$ Relaxor Dielectric Ceramics: Part1, Dielectric Properties", J. Am. Ceram. Soc., 76
(1993)454-458.

11) H.Kanai, O.Furukawa, S.Nakamura and Y.Yamashita: "Effect of Stoichiometry on the Dielectric Properties and the life Performance of $\left(\mathrm{Pb}_{0.875} \mathrm{Ba}_{0.125}\right)\left[\left(\mathrm{Mg}_{1 / 3}\right.\right.$ $\left.\left.\mathrm{Nb}_{23}\right)_{0.5}\left(\mathrm{Zn}_{1 / 3} \mathrm{Nb}_{23}\right)_{0.3} \mathrm{Ti}_{0.2}\right] \mathrm{O}_{3}$ Relaxor Dielectric Ceramics: Part 2, Life Performance", J. Am. Ceram. Soc., 76 (1993)459-464.

12) S.S.Cole,Jr.: "Oxidation and Reduction of Palladium in the Presence of Silver", J. Am. Ceram. Soc., 68 (1985)C106-C107.

13) R.L.Rowland and N.H.Nachtrieb: "Self-Diffusion of Palladium in Silver-Palladium Alloys", J. Phys. Chem., 67(1963)2817-2821.

14) T.C.Pluym and T.T.Kodas: "Silver-Palladium Alloy particle production by spray pyrolysis", J. Mater. Res., 10(1995)1661-1673.

15) J.G.Pepin: "Subsolidus Phase Relation in the System Pd-Ag-O and Application to Multilayer Ceramics Capacitor Electrodes", Advaced Ceram Mater., 3 (1988)517-519.

16) T.Ueyama, H.Wada and N.Kaneko: "Pulverization and Dispersion Technique for Agglomerated Particles of Alumina Powder in a Slurry", J. Am. Ceram. Soc., 71 (1988)C74-77. 